\title{
O SERTANEJO: CAMINHOS E (DES) CAMINHOS DA LIBERTAÇÃO
}

\author{
Angela Luzia Miranda* \\ Leonardo da Rocha Bezerra de Souza ${ }^{* *}$
}

\section{Resumo}

Ao longo do Século XX, ocorreram diversas mudanças no cenário geopolítico e cultural brasileiro, em especial na região nordeste, onde o fluxo de migrantes para a região sudeste do Brasil (SP, MG, RJ) provocou grandes transformações na vida do nordestino, trabalhador do campo, também chamado de "sertanejo", do ponto de vista da sua identidade cultural. A identificação deste processo está evidenciada na obra do cantor e compositor Luiz Gonzaga (1912 - 1989), que retratou as muitas fases e faces dessas transformações, demonstrando, através da música, os impactos sofridos pelos sertanejos, do ponto de vista da sua cultura. Este trabalho propõe analisar, através da obra de Luiz Gonzaga, o confronto do sertanejo em termos de cultura e identidade, com o novo cenário em que foi submetido, involuntariamente, através do processo migratório para as regiões mais industrializada do país. Analisaremos estes recortes através das categorias da Filosofia da Libertação, como: Alienação, Totalidade e, sobretudo, através da categoria de Exterioridade, presentes na obra do filósofo argentino Enrique Dussel.

Palavras Chave: Filosofia da Libertação. Sertanejo. Luiz Gonzaga.

\begin{abstract}
Throughout the twentieth century, several changes occurred in the Brazilian geopolitical and cultural scene, especially in the northeast, where the flow of migrants to southeastern Brazil (SP, MG, RJ) has caused major changes in the point of view of cultural identity : life in the northeast, field worker (also called "Sertanejo"). The identification of this process is evident in the background work of the singer and composer Luiz Gonzaga (1912 - 1989), who portrayed the many phases and faces of these transformations, characterizing the impacts suffered by backwoodsmen, from the point of view of their culture. This paper aims to analyze through the background work of Luiz Gonzaga, the confrontation of the Sertanejo (in terms of culture and identity) with the new scenario in which it was included (involuntarily). We will analyze these thematic clippings through the category of Exteriority, brought by the Argentinean philosopher Enrique Dussel.
\end{abstract}

Key Words: Philosophy of Liberation. Sertanejo. Luiz Gonzaga.

\footnotetext{
* Doutora em Filosofia pela Universidade de Salamanca (ES); Doutora em Ciencia, Tecnología y Sociedade pela Universidad del País Vasco. Professora de Ética em Ciência e Tecnologia da Escola de Ciências e Tecnologias, Universidade Federal do Rio Grande do Norte, Natal/RN, Brasil. Coordenadora Grupo Phrònesis: Estudos em Filosofia, Ciência, Tecnologia e Sociedade (UFRN). E-mail: angelalmiranda@gmail.com. CV: http://lattes.cnpq.br/2841293474679022.

** Bacharelado em Comunicação Social - Jornalismo, UFRN, Natal, RN, Brasil. Membro do Grupo Phrònesis: Estudos em Filosofia, Ciência, Tecnologia e Sociedade (UFRN). E-mail: 1rb.souza@gmail.com. CV: http://lattes.cnpq.br/1400670385958208.
}

DIALEKTIKÉ, v. 1, novembro 2014, p. 50-65

Artigo submetido e aceito em novembro/2014 


\section{INTRODUÇÃO}

Este trabalho tem como propósito analisar a obra do cantor e compositor brasileiro Luiz Gonzaga (1912 - 1989) desde um olhar crítico, considerando o pensamento da Ética e da Filosofia da Libertação. Pretende-se percorrer os meandros que envolvem as transformações de identidade e cultura da figura do sertanejo ${ }^{1}$ do nordeste brasileiro em seus fluxos de migração. Para tanto, através das músicas de Gonzaga, será observado a construção e a reconstrução histórica de sua cultura e identidade, marcadas pela mescla de características oriundas da colonização e pós-colonização do Brasil e da terceira e quarta década do século XX, onde historicamente encontramos o perfil do migrante mais presente na obra de Luiz Gonzaga. Este recorte temporal e espacial da figura do sertanejo do nordeste brasileiro será analisado a partir da categoria da Exterioridade, presente na Filosofia e na Ética da Libertação.

No decorrer deste trabalho serão levantados aspectos diretamente ligados à formação do povo nordestino e ao contexto no qual estavam ou foram inseridos. Esta análise também será realizada através das categorias de Totalidade e Alienação, que contribuirão para uma maior explanação sobre o tema. É a Totalidade que garantirá a visualização da cultura e identidade do povo sertanejo, bem como seu rompimento através da Alienação, colocando-o como ser externo ao meio. E é a Alienação que elucidará os fenômenos que contribuíram para inserção desse grupo social numa zona de Exterioridade.

\section{RECORTE HISTORIOGRÁFICO}

Antes de tudo, precisamos contextualizar como surgiu a conjuntura apresentada, tanto para Luiz Gonzaga, como ao contexto base de sua obra. Dessa forma recorremos às raízes do Nordeste do Brasil, desde a colonização (1500 - 1822). Segundo Sampaio (2003):

O ouro, tão procurado, só foi descoberto (em quantidades apreciáveis) no fim do século XVII, de modo quedurante todo século XVI o Brasil foi uma colônia de importância secundária para Coroa portuguesa. Mas, ao final desse século e princípios do século XVII, o açúcar tornou-se uma mercadoria de grande

\footnotetext{
${ }^{1}$ Sertanejo: Adj. 1. Do Sertão. 2. Que habita o sertão (FERREIRA, 1999, p. 1845).

DIALEKTIKÉ, v. 1, novembro 2014, p. 50-65

Artigo submetido e aceito em novembro/2014
} 
importância no mercado internacional. O Brasil, especialmente a região nordeste, reunia condições muito favoráveis para o estabelecimento de uma grande exploração açucareira. Isso determinou um novo tipo de relacionamento entre metrópole e a colônia. (SAMPAIO, 2003, p. 9)

Conforme apresentado, a colônia portuguesa (Brasil) tem seu relacionamento de exploração com a coroa portuguesa. Em síntese: o sul possuía o ouro, o nordeste litorâneo enveredava pelos caminhos da cana-de-açúcar. Durante aproximadamente três séculos o Brasil foi explorado em torno desses dois modos de economia. Prosseguindo com uma esquematização desses cenários, Sampaio (2003) ainda comenta a rentabilidade da economia cafeeira, no sudeste já do século XIX e também percorrendo as duas primeiras décadas do século seguinte. Mais uma vez, há um novo modelo de economia, ou novos centros de poder econômico. Este recorte é importante por ser ele o elemento catalisador para formação da conjuntura sociocultural do país.

A extensa formação sociocultural do Brasil é complexa, cheia de curvas sinuosas, entretanto, essencial para a compreensão dos fenômenos que construíram e reconstruíram os brasileiros e seus grupos sociais. Essa formação é primorosamente retratada pelo antropólogo Darcy Ribeiro (1922 - 1997) em seu livro "O Povo Brasileiro". Darcy conceituou essa formação histórico-cultural como "brasis", pois, a formação do povo brasileiro não é constituída de apenas uma única história, um único processo formador e sim vários. São vários fatores e aspectos constitutivos que identificam a sociedade brasileira, identificados em etapas, alcançando, inclusive, o contexto da obra de Gonzaga. No caso deste trabalho, esta etapa está situada entre os anos de 1930 até 1950. Darcy conceituou a formação sociopolítica pós-colonial em diversas frentes de culturas: crioula, cabocla, sertaneja, gaúcha. Dentre essas culturas, vamos nos ater à sertaneja.

\section{BRASIL SERTANEJO}

Sobre o Nordeste brasileiro, Darcy Ribeiro escreve:

Para além da faixa nordestina das terras frescas e férteis do massapé, com rica cobertura florestal, onde se implantaram os engenhos de açúcar, desdobremse as terras de uma outra área ecológica. Começam pela orla descontínua ainda úmida do agreste e prosseguem com as enormes extensões semiáridas das caatingas. Mais além, penetrando já o Brasil Central. Toda essa área conforma um vastíssimo mediterrâneo de vegetação rala, confiando, de um lado, pela 
floresta da costa atlântica, do outro pela floresta amazônica e fechado ao sul por zonas de matas e campinas naturais. (RIBEIRO, 2013, p. 306)

O Nordeste brasileiro foi dividido em dois espaços distintos: (i) zona litorânea, economia a base da cana-de-açúcar e seus engenhos; (ii) agreste e caatingas, onde "desenvolveu-se uma economia pastoril associada originalmente à produção açucareira como fornecedora de carne, de couros e bois de serviço. Foi sempre uma economia pobre e dependente" (RIBEIRO, 1995, p. 337). É em torno desse segundo espaço que nos debruçaremos. Foi nesse sertão seco que o sertanejo, cantado por Gonzaga, constituiu suas raízes.

A cultura sertaneja consolidou-se nesse sertão de crises e de luta com o meio-ambiente, enfrentando períodos de seca. Construiu-se no meio desse semiárido, grandes latifúndios, começando pela pecuária e estendendo-se até o século XX com as grandes plantações de algodão. O ritmo das chuvas fazia com que houvesse uma longa rotatividade entre esses espaços. Daí nasceram os "retirantes" que cortavam a região nordeste em busca de terras, ou um lugar ("canto") melhor para se viver. Não que os demais habitantes desse pedaço do Brasil estivessem livres desse fado, mas o que ocorre é que eles possuíam outras relações sociais e culturais, que vislumbraremos mais adiante.

Além desta densa formação, ou seja, desse processo geopolítico de muitas faces, muitos outros fenômenos contribuíram para conjuntura cultural na qual estava envolvido o sertanejo, no início do século XX. Entre estes, destacam-se a comunicação e os transportes, tendo especial importância o primeiro. Os processos de comunicação, em especial o rádio, contribuíram significativamente para a construção desse mapa de culturas no país, dando início a um processo de interculturalidade ainda mais amplo que o primeiro, iniciado com a colonização em prol da sustentação de economias regionais-coloniais, expressas anteriormente.

\section{GONZAGA E O PODER DA COMUNICAÇÃO}

Nascido na zona rural de Exú, cidade do interior pernambucano, região nordeste do Brasil, Luiz Gonzaga do Nascimento era filho do agricultor e tocador Januário e de Dona Santana. Gonzaga viu em sua infância o trato com a terra e a pecuária e cresceu num ambiente de musicalidade, vivenciando os costumes e festas típicas da região. Sua obra adquire força com sua ida para o sudeste já na década de trinta, onde solidifica sua carreira como cantor e compositor. Sua obra envolve, além de composições próprias, músicas e poemas de outros 
nomes no nordeste brasileiro, como Patativa do Assaré, Zé Dantas, João Silva, entre outros. Gonzaga conseguiu compreender dentro de sua musicalidade muitas faces e fases importantes da história desse povo e, por isso, tornou-se um ícone da música brasileira no tocante à representação da cultura e da identidade do sertanejo e de sua vida no sertão.

É no início dos anos de 1940 que a obra do intérprete ganha reconhecimento, inclusive no próprio Nordeste do Brasil. Segundo Albuquerque Júnior (1999), o avanço nos transportes e no rádio se tornaram partes importantes desse processo migratório retratado por Gonzaga. $\mathrm{O}$ rádio era o principal equipamento de comunicação da época. Sua programação espelhava-se no discurso nacionalista - na busca por uma identidade única do Brasil - propagandeado pelo governo, que também passava a veicular a busca por mão-de-obra necessária para manter a industrialização do país.

É neste cenário que Gonzaga adquire seu espaço na mídia, tornando-se o expoente da cultura nordestina; era a voz dos nordestinos, também ouvida no Sul do país. Do ponto de vista do sertanejo, era através do rádio que emergia a possibilidade de sair do trágico regime de seca do sertão nordestino e era a oportunidade do sertanejo de sobreviver em outro lugar, longe da saga de sua terra natal, anunciada pela propaganda desenvolvimentista que soprava desde as regiões Sul e Sudeste do Brasil; era a introdução a uma nova cultura, novos movimentos e conhecimentos. Noutra vertente, também era a oportunidade de libertar-se dos regimes políticos regionais, baseados no coronelismo e nos resquícios da relação Senhor e Escravo, da "Casa Grande e da Senzala" - para usar a mesma expressão de Gilberto Freire (2004) ao retratar a cultura brasileira. $\mathrm{O}$ rádio transmitia uma mensagem de que era o momento de integração e do progresso nacional. Neste contexto, Albuquerque analisa o sentido da migração:

A melhoria dos transportes e dos meios de comunicação, como: correios,
jornais de circulação nacional e, principalmente, a presença do rádio como
grande veículo de comunicação de massas desde a década de trinta, torna as
notícias das oportunidades no Sul, constantemente propagandeadas por
governos e instituições interessadas na atração desta mão-de-obra, um
estímulo crescente para a migração. Esta é festejada pelo discurso nacionalista
como fator de integração nacional, um fator de encontro e interpenetração dos
"dois Brasis" que ameaçavam se distanciar irremediavelmente. As grandes
cidades do Sul seriam enfim o lugar onde se gestaria a cultura nacional de há
muito perseguida. [...] A migração adquire muitas vezes um caráter libertador:
a fuga de um mando insuportável, de uma exploração econômica
(ALBUQUERQUE JÚNIOR, 1999, p. 152).

DIALEKTIKÉ, v. 1, novembro 2014, p. 50-65

Artigo submetido e aceito em novembro/2014 
É aqui que encontramos o cenário que une a vida do sertanejo, retratado na obra de Luiz Gonzaga, e a corrente da Filosofia e da Ética da Libertação, tal como mostraremos a seguir.

\section{A ÉTICA DA LIBERTAÇÃO E SUAS CATEGORIAS}

Segundo Miranda,

A ética da Libertação surge na década de 80, quando pensadores do continente latino-americano começam a fundar um novo modo de fazer Filosofia e pensar a Ética, baseando-se na categoria da "libertação". Para esses pensadores, o continente americano e todos os países foram marginalizados no processo de História do Pensamento Ocidental (MIRANDA, 2007, p. 5).

Este modelo ético propõe uma nova forma de agir, respeitando o outro. Mudanças na forma de tratarmos e visualizarmos o outro, vendo-o realmente como outro; alguém distinto, com identidade e cultura própria, bem como o direito de exercê-las, tal como observa Dussel: "Esta é uma ética da vida, ética crítica a partir das vítimas. [...] São as vítimas, quando irrompem na história, que criam o novo. Sempre foi assim. Não pode ser de outra maneira" (DUSSEL, 2005, p. 501). O nascimento dessa ética, no Brasil, ainda culmina com o continuo êxodo no sentido Nordeste-Sudeste, que durou mais especificamente de 1930 até 1980, ou seja, da Era Vargas ao milagre econômico brasileiro (Regime Militar), com um enfoque maior para essa migração das duas décadas de 1930 a 1940.

É neste sentido que vislumbramos as perspectivas para analisar o sertanejo retratado por Gonzaga: o processo migratório do sertanejo que atravessa o país, fugindo da seca e em busca de uma vida melhor prometida pelo desenvolvimento das regiões Sul e Sudeste do Brasil, é o retrato da relação com o outro, a alteridade.

E, para melhor elucidar estes aspectos, interessa-nos, em especial, as seguintes categorias da Filosofia da Libertação: (1) Totalidade: "Todo mundo é uma totalidade. Totalidade indica limites de limites" (DUSSEL, 1977, p. 29). Assim cada ser humano deve possuir sobre si o direito de gestão, independente das influências exercidas pelo meio; cada grupo cultural ou/e de identidade tem o direto sobre seu ser e de agir dentro de sua totalidade.

(2) Alienação: “[...] alienar é vender alguém ou algo; é fazê-lo passar a outro possuidor ou proprietário. A alienação de um povo ou indivíduo singular é fazer-lhe perder seu ser ao incorporá-lo como momento, aspecto ou instrumento de outro ser” (DUSSEL, 1977, p. 58). (3)

Exterioridade: "[ela] quer indicar o âmbito onde o outro homem, como livre e incondicionado 
por meu sistema e não como parte de meu mundo, se revela" (DUSSEL, 1977, p. 47). Aqui ela é percebida dentro do sistema em que o indivíduo/sertanejo é posto, que compreende a sua vida pós-uterina até a sua migração no início do século; é um limite existente entre o ser e o outro.

\section{A LEITURA DO SERTANEJO A PARTIR DA ÉTICA DA LIBERTAÇÃO:}

A proposta da Ética da Libertação incide sobre o sertanejo desde vários aspectos. Neste sentido, “A Triste Partida” (1980), obra-prima de Luiz Gonzaga, pode ser considerada a fiel imagem do que foi essa migração e todos os fatores encontrados nos caminhos e descaminhos da migração do sertanejo. É nesta obra que encontramos as partes fundamentais da relação com o sentido de Libertação como categoria fundamental do pensamento de Dussel, seja do ponto de vista filosófico ou ético.

Gonzaga canta:

[...] A treze do mês/ Ele fez experiência/ Perdeu sua crença/ Nas pedras de sal [...] Mas noutra esperança/ Com gosto se agarra/ Pensando na barra/ Do alegre Natal [...] Rompeu-se o Natal/ Porém barra não veio/ O sol bem vermeio/ Nasceu muito além [...] Na copa da mata/ Buzina a cigarra/ Ninguém vê a barra/ Pois barra não tem [...] Nóis vamo a São Paulo/ Viver ou Morrer/ Nóis vamos a São Paulo/ Que a coisa tá feia/ Por terras alheia/ Nós vamos vagar [...] Se o nosso destino/ Não for tão mesquinho/ Ai, pro nosso cantinho/ Nóis torna voltar [...] E vende seu burro/ Jumento e o cavalo/ Inté mesmo o galo/ Venderam também [...] Pois logo aparece/ Feliz fazendeiro/ Por pouco dinheiro/ Lhe compra o que tem/ Ai, ai, ai, ai/ Em um caminhão/ Ele joga a famia/ Chegou o triste dia/ Já vai viajar [...] A seca terrívi/ Que tudo devora/ Ai,lhe bota pra fora/ Da terra natal [...] O carro já corre/ No topo da serra/ Oiando pra terra/ Seu berço, seu lar [...] Aquele nortista/ Partido de pena/ De longe acena/ Adeus meu lugar [...] No dia seguinte/ Já tudo enfadado/ E o carro embalado/ Veloz a correr [...] (GONZAGA, L. 1980)².

Abre-se com esta música um universo de faces que analisaremos na perspectiva não só da categoria da Libertação, como também de cada categoria e de cada sistema de opressão. A Totalidade que compõe o sertanejo; a Alienação, sistema e práticas que condicionaram o nordestino e, por último, a Exterioridade, condição máxima deste drama que agrega pouquíssima ficção e muitas mortes e mutilações.

\footnotetext{
${ }^{2}$ Compositor: Patativa do ASSARÉ, 1953.

DIALEKTIKÉ, v. 1, novembro 2014, p. 50-65

Artigo submetido e aceito em novembro/2014
} 


\subsection{A TOTALIDADE:}

O sistema de migração retratado por Gonzaga avança sobre a história trazendo de volta valores, ou ausência crítica deles, a cada período histórico. Pelo viés da Totalidade, podemos ver o universo em que os sertanejos cresceram: formaram uma cultura e uma identidade própria. No entanto, ela estava subordinada, ainda que no sertão, às duras relações de clima e de poder, como em "A Triste Partida" (1980) e "Coronel Pedro do Norte" (1971). A Totalidade, que representava cada um dos sertanejos, era desrespeitada por vedar-lhes a liberdade de escolha. Sem possibilidade de permanência no sertão (ainda que com toda sua resistência), o sertanejo tinha sua cultura e identidade confrontada e violada, e lhe era ensinado a ser impotente, como em “Asa Branca” (1962). Não havia outra saída; era necessário ceder aos mandos e desmandos de outro sistema-mundo.

Gonzaga canta:

"Lá no meu sertão pro cabôco lê/ tem que aprender um outro $\mathrm{ABC} / \mathrm{O} \mathrm{J}$ é Ji, o L é Lê/ O S é Si, mas o R tem nome de rê/ O J é Gi, o Lé Lê/ O S é Si, mas o $\mathrm{R}$ tem nome de rê/ Até o Y, lá é "pissilone"/ O M é Mê e o N é Nê/ O F é Fê, o G chama-se Guê/ Na escola é engraçado/ Ouvir-se tanto Ê/ A, Bê, Cê, Dê/ Fê, Guê, Lê, Mê/ Nê, Pê, Quê, Rê/ Tê, Vê e Zê"' (GONZAGA, L. 1953)

E é partindo deste $\mathrm{ABC}$ cantado, que nosso interprete alcança uma das primeiras características da identidade desse habitante do semiárido. Isto é, o alfabeto, a linguagem criada e praticada. É também a primeira amostra da identidade construída, marca do confronto desigual que o sertanejo enfrenta na sua migração para o Sul. A totalidade identitária do sertanejo é confrontada com o novo ambiente. Gonzaga canta em "Boiadeiro" (1951) e em "Cigarro de Paia" (1984) as fortes marcas dessa identidade: maneira de comportar-se, sua relação com a família e com o meio, suas marcas estéticas, entre outras:

Vai boiadeiro que a noite já vem/ Guarda o teu gado e vai pra junto do teu bem/ De manhãzinha quando eu sigo pela/ estrada/ Minha boiada pra invernada eu vou levar/ São dez cabeça, é muito pouco quase nada/ Mas num tem outras Mais bonitas no Lugar [...] De tardezinha quando eu venho pela estrada/ A fiarada tá todinha a me esperar/ São dez fiim, é muito pouco quase nada/ Mas num tem outros Mais bonitos no lugar [...] E quando eu chego na cancela da morada/ Minha Rosinha vem correndo me abraçar/ É pequenina, é miudinha, é quase nada/ Mas num tem outra mais bonita no lugar [...] (GONZAGA, L. 1951). 
Meu cigarro é de paia/ Meu cavalo ligeiro/ Minha rede de maia/ Meu cachorro trigueiro/ Quando a manhã vai clareando/ Deixo a rede a balançar/ No meu cavalo vou montando/ Deixo o cão pra vigiar/ Cendo o cigarro vez em quando/ Pra esquecer de me alembrar/ Que só me falta uma bonita morena/ Pra Mais nada me faltar (GONZAGA, L. 1984).

O habitante da caatinga construiu ao longo dos anos e das transformações uma cultura riquíssima; uma mescla entre as mutações impostas pelo sistema-mundo em que foi colocado, ísto é, homens e mulheres frutos de uma colonização regada ao esquecimento e à exploração de recursos naturais e humanos. Gonzaga interpreta em "São João Sem Futrica" (1984) sua vontade de manter essas tradições, como a festa de São João. É o "Olha pro Céu” (1965) que representa aquele espetáculo de saudade e vontade de voltar a ser aquilo que guarda dentro de si.

O universo dessa cultura se estende pelo canto da "Acauã" (1984) que espanta a chuva, segue em "O Cheiro de Carolina" (1984) que o deslumbra "Numa Sala de Reboco" (1964), alcança o infinito com “A Volta da Asa Branca" (1982) e a possibilidade de retorno ao seu lar. Em outros termos: é a voz de Gonzaga que assegura a difusão da cultura sertaneja. Em sua voz o regresso ainda é a esperança:

Já faz três noite que pro Norte relampeia/ A Asa Branca ouvindo o ronco do trovão/ Já bateu asas e vortô pro meu sertão/ Ai, ai, eu vî m'imbora/ Vô cuidá da prantação/ A seca fez eu dissertar da minha terra/ Mas felizmente Deus agora si alembro/ De mandá chuva pr'esse Sertão sofredô/ Sertão das muié séra/ Dos home trabaiadô/ Rios correndo, as cachoeira tão zuando/ Terra moiada, mata verde, que riqueza/ $\mathrm{E}$ a asa branca à tarde canta, que beleza!/ $\mathrm{Ai}$, ai o povo alegre/ Mais alegre a natureza/ Sentindo a chuva me arrescordo de Rosinha/ A linda frô do meu Sertão pernambucano/ E se a safra num atrapaiá meus prano/ Que é que hai, ô seu vigaro?/ Vô casá no fim do ano! (GONZAGA, L. 1982)

Em outros termos, "A Triste Partida" (1980) é o que nos leva ao confronto e é a expressão da agressão sofrida pelo sertanejo que, nesse momento, marca a sua identidade e a sua cultura. Assim Gonzaga canta: "Chegaram em São Paulo/ Sem cobre quebrado/ E o pobre acanhado/ Percura um patrão/ Meu Deus, meu Deus/ Só vê cara estranha/ De estranha gente/ Tudo é diferente/ Do caro torrão [...] Trabaia dois ano/ Três ano e mais ano" (GONZAGA, 1980, p. 6). Aqui elucida-se a dicotomia dos dois modos de vida experimentado pelo sertanejo. Gonzaga elucida, nessas composições, posições claras do antes e depois da migração. O sertanejo tem sua totalidade desprezada e entregue ao sistema sulista de produção; lá ele é mutilado 
culturalmente e identitáriamente, no mesmo compasso em que a política de governo expressa a difusão do Nordeste nos rádios, através da própria participação de Luiz Gonzaga.

A opressão marca a mutação da totalidade, que é e envolve o sertanejo, castiga-o impondo-lhe novos costumes, novas vestimentas, novo modo de fala e entendimento.

\subsection{A ALIENAÇÃO:}

Do ponto de vista da categoria da Alienação, o sertanejo sai de um sistema, onde havia construído sua identidade e crescido dentro da sua cultura (mas não isentos de alienação, tanto pela política local, como pelos meios de comunicação), passando a encontrar uma possível solução para seus problemas - pelo menos com a seca - com a sua partida para o Sul do país. Mas novamente aqui ele se vê alienado por um sistema diferente. Apesar da visão de solução, sabia das dificuldades a serem enfrentadas no novo sistema-mundo, mas era levado a crer que só poderia sobreviver, partindo. Assim, ao partir, era obrigado a deixar para trás o modo de vida de seus antepassados.

Este panorama é descrito pelo "Rei do Baião" (como era conhecido Gonzaga), quando mostrou as relações de sanção sofridas pelos sertanejos, por exemplo, ao retratar o abandono de sua fogueira para comemorar a festa de São João, em “São João sem Futrica” (1984). Assim, o sertanejo era vítima da alienação de governos e instituições que o "convencia" a abandonar seus costumes. Era alienado por acreditar que seu conhecimento era inferior; por acreditar que teria de sair do seu sertão para sobreviver e era obrigado a (re)construir sua identidade e sua cultura em outro lugar.

O rádio era (em alusão a BULFINCH, 2006): o Caronte, o barqueiro que, no rio de areia entre sertão e cidade grande, fazia a travessia do sertanejo; também era a parca que cortava o fio da vida, esperança de continuar no sertão de cada família; era o cavalo de troia, aquele presente que dentro de casa operava mudanças radicais. De modo mais concreto, esses papéis passavam a ser exercidos pelos meios de transporte (o pau-de-arara), logo depois pela vida no Sul. Em uma ação alienadora e opressora, a comunicação incitava o progresso do Sul e as dificuldades no Nordeste. Em alguns casos a própria musicalidade de Gonzaga transmitia esta mensagem, como em "Vozes da Seca" (1970), onde havia um reconhecimento de uma inferioridade e de um esquecimento, tal como se observa: 
Seu doutô, os nordestino/ Têm muita gratidão/ Pelo auxílio do sulista/ Nesta seca do sertão/ Mas doutô, uma esmola/ A um home que é são/ Ou lhe mata de vergonha/ Ou vicía o cidadão/ É por isso que pedimo/ Proteção a vomicê/ Home por nós escoído/ Para a rédias do podê/ Pois doutô dos vinte Estado/ Temos oito sem chuvê/ Veja bem, quase metade/ Do Brasil tá sem comê/ Dê serviço ao nosso povo/ Encha os rio de barrage/ Dê comida a preço bão/ Não esqueça açudage/ Livre assim nós da esmola/ Que no fim dessa estiage/ Lhe pagamo até os juro/ Sem gastar nossa corage/ Se o doutor fizer assim/ Salva o povo do sertão [...] (GONZAGA, L. 1970)

Como percebemos, o sertanejo, ainda que numa situação de alienação, por ser levado a crer que tinha que deixar sua terra, tinha forte apego ao sertão. O sertanejo mais do que apegado ao sertão, mantinha-se preso ao seu sentido de ser, numa condição de esperança, de resgate da sua própria condição de ser (ser + tanejo= homem do sertão). Resistindo a essa partida, ele se envolvia no mesmo sentimento expressado pelo Rei do Baião, e indagava-se: Até quando resistir? De um lado a oferta de sobrevivência no sudeste, do outro, a espera da chuva e as pressões do rico fazendeiro, que por pouco dinheiro (A Triste Partida, 1980) lhe compraria o que tinha e só assim este trabalhador partiria.

Como dito anteriormente, os coronéis, donos de grandes latifúndios, formavam um dos quadros de opressão e, mais que isso, tornavam-se coniventes com o processo de alienação. Esses coronéis exerciam sobre os pequenos agricultores um domínio considerável, tanto na vida dentro do Nordeste como fora, e este fator contribuía de forma contundente para tomada de decisões. Era oportuno que para o sertanejo tentar salvar sua vida e de sua família, possuísse algum dinheiro para ir à cidade grande, vendida como o grande centro de oportunidade, tal como era propagado pelo rádio. A sua vez, o coronel exercia esse papel de financiador e mediador deste processo.

Em suma: O rádio exercia a influência e a propagação de uma possível solução para os problemas da seca e da fome do sertanejo; o coronel financiava essa ida, comprando a terra do sertanejo, aumentando o seu latifúndio e o pau-de-arara levava o sertanejo para o Sul.

\subsection{A EXTERIORIDADE:}

Do ponto de vista político, o governo abandonou o sertanejo no sertão durante as duas primeiras décadas do século XX, sem apresentar nenhuma ação governamental efetiva para solucionar o problema da seca. Logo depois, o mesmo governo lucraria com sua migração, abandonando-o nas mãos de seus patrões, nas cidades do Sul Brasil. Ou seja, o sertanejo é visto 
como produto e capital. Aqui vemos a violação dos limites da Exterioridade. Esse outro era a vítima do enfraquecimento de seus laços culturais e de sua identidade. Era agora obrigado a não exercer suas atividades de tradição e as relações sociais originárias, inclusive com o meioambiente e seu habitat.

Essa condição de Exterioridade era a ação mais contundente do sistema opressor, uma vez que, no sertão, o sertanejo convivia com as duras relações de poder político. O sertanejo estava sujeito aos mandos e desmandos de um líder regional: o coronel. Em "Coronel Pedro do Norte" (1971), Gonzaga canta o poder que o coronel possuía sobre a terra e o povo, o mesmo canto, aparece também em "A Triste Partida" (1980), onde possivelmente o coronel compraria sua terra por pouco dinheiro.

Assim, no ambiente do semiárido, desde o período caracterizado como cultura econômica da pecuária, “o criador e seus vaqueiros se relacionavam como um amo e seus servidores. Enquanto dono e senhor, o proprietário tinha autoridade indiscutida sobre bens e, às vezes, pretendia tê-la sobre as vidas e, frequentemente, sobre as mulheres que lhe apetecessem" (RIBEIRO, 2013, p. 309). Essa relação era a condição mais básica para se mostrar o quão hostilizado era o povo do semiárido. Esse grupo passa a compor o fenômeno de Exterioridade no entorno do mapa fluxo. Era visível já no semiárido a violação à Totalidade do sertanejo, que culminava em uma composição familiar externa ao seu próprio meio; essa condição de externo ao meio, foi fator de relevante na decisão de partir ou não de sua terra natal. Portanto, não era apenas a seca e os períodos de seca que contribuíam para essa locomoção eixo Nordeste-Sul, mas uma gama de fatores, que se apresentavam como alternativa e medida frente à morte ou a eterna submissão do sertanejo ao coronel.

Outro fator fundamental para a dinâmica migratória eram os mecanismos de Alienação exercidos pelo rádio e pelas construções sociais as quais esse povo esteve submetido. Essas construções sociais, por sua vez, também colocaram o migrante do Nordeste em outro aspecto de Exterioridade, pois ele agora estava submetido ao regime de seca, a venda de uma solução aos seus males, a continuidade de um regime de exploração. Quem ousa ir contra a possibilidade de libertação, ainda que esta seja de se ver livre da morte, ou ser livre do seu senhor (considerando a relação senhor versus escravo)? Com o nordestino não seria diferente, ele partia em busca de uma solução, abria mão de sua cultura e escondia sua identidade.

Essa condição de Exterioridade enquadrou não apenas os oriundos do Nordeste como também, alcançou os patamares regionais, com a própria dinâmica de êxodo rural provocado 
no próprio Sul e Sudeste do Brasil. No entanto, abandonada e dependente, a região do Nordeste é o exemplo da geopolítica excludente. Como nos diz Riberio (2013), sobre as zonas de pastoreio (semiárido):

Mais tarde, o aumento da população, as zonas de pastoreio transformaram-se, principalmente, em criatórios de gente, dos quais saem os contingentes de mão-de-obra requeridos pelas demais regiões do país. (Darcy explana sobre as diversas culturas, em especial a sertaneja) Assim, também, para engrossar as populações urbanas, sempre que um surto de construção civil ou de industrialização exigia massas de mão-de-obra não qualificada.

Os Sertões se fizeram, desse modo, um vasto reservatório de força de trabalho barata, passando a viver, em parte, das contribuições remetidas pelos sertanejos emigrados para sustento de suas famílias. (RIBEIRO, 2013, p. 313)

Essa sistemática ainda é retratada por Luiz Gonzaga: [...] Pois logo aparece um feliz fazendeiro, por pouco dinheiro the compra o que tem (A Triste Partida, 1980). Esse sistema dominador, invasor da totalidade do sertanejo, presente no poder do coronel (senhor) violava o homem/mulher do sertão como indivíduo e comunidade. Não havia o reconhecimento de uma alteridade: o limite exposto por Dussel (1986) em que seria a capacidade de colocar-se em prol do Outro, mesmo ciente da política de inferioridade entre regiões ou entre outras esferas de poder.

O sistema de Alienação (governos, instituições de comunicação como o rádio e outras partes) apresentou oportunidade, muitas vezes irreais, pois o sistema era tão explorador quanto a dinâmica do Nordeste seco, entre elas: fugir da opressão que vivia no sistema político e social do semiárido; sair do trágico regime de secas. Ambas as hipóteses levavam a perda de um pedaço de si. Ao sair do nordeste, o migrante ingressava na derrubada de costumes, na mudança de valores, etc.

O "vasto reservatório de força de trabalho" (RIBEIRO, 2013, p. 313) transbordava a medida que havia necessidade de expandir o território do Sul. O sertanejo embarcava e em sua chegada já se encontrava como figura externa (heterogênea), figura ímpar num oceano cultural e de novas identidades. Não era mais o coronel que iria determinar o que vestir, nem como se portar ou trabalhar, quem realizava estas determinações era outro patrão. A selva era de pedra; em vez de carroças, carros.

O sertanejo não era tratado como ser humano distinto, como propõe os princípios da Ética da Libertação, mas sim como diferente, fora do padrão - era necessário se adequar ao padrão de normalidade e funcionalidade do novo meio social. É a opressão do novo sistema 
cultural e de identidade, que transforma o sertanejo em trabalhador no Sul, além de tê-lo inserido no novo mundo de preconceitos e discriminação; homem/mulher sem existência, violado, deformado culturalmente e identitariamente.

\section{CONSIDERAÇÕES FINAIS}

A Ética da Libertação, cujo ponto de partida é o excluído, encontra na obra de Luiz Gonzaga as características necessárias desde onde deve partir sua crítica ao sistema-mundo vigente. No Brasil, os sertanejos formam um grupo social que historicamente foram violentados cultural e identitariamente. A saga da migração do sertanejo em busca de uma vida melhor na cidade, tão bem retratada na obra de Luiz Gonzaga, representa o sentido de vítima do sistemamundo, analisado por Dussel como condição originária da Ética.

E vale lembrar que esse povo ainda continua sendo vítima, e que hodiernamente continua seu calvário, surgindo e ressurgindo na voz de Gonzaga, a partir de sua obra sem precedentes, que coleciona histórias, fatos e críticas (dos mais diversos ângulos e autores), e que ainda hoje possui uma dimensão extraordinária, do ponto de vista do retrato do homem do sertão nordestino.

Neste sentido, a Ética e a Filosofia da Libertação tem seu papel na continuidade da luta pela libertação deste grupo social, identificando e denunciando as violações éticas, étnicas e morais, a fim de garantir aos novos nordestinos, descendentes desse grupo social migrante, a recuperação da sua história, sua construção social e sua identidade cultural. Inclusive, no sentido de resgatar a história de seus antepassados, excluídos e sem poder de escolha e, ao mesmo tempo, contribuintes (sem reconhecimento) da construção de uma sociedade de excluídos e oprimidos.

Ademais, a Ética e Filosofia da Libertação tem o papel de convidar a entender a dinâmica da exclusão que ainda insiste em ser o discurso vigente. É aqui que reside a contribuição e o legado da obra de Luiz Gonzaga, trazendo esta história cantada em versos que representam o pranto do sertanejo, cujo intuito maior é dar voz a quem lhes foi negada. É neste sentido que avaliamos a necessidade de dar prosseguimento às pesquisas e às ações que busquem, mais do que analisar a realidade, postular a dignidade, o reconhecimento e a liberdade do outro de ser e estar no mundo. 
Neste sentido, é proposta deste trabalho também a denúncia, o reconhecimento e a mobilização. Denúncia das imposições e violações sofridas por esse povo e que em pleno século XXI se repetem de maneira distinta, bem como denúncia da perda de valores éticos e morais da região Nordeste do Brasil que, ao longo do tempo, se perdem nos riscos da história única, contada superficialmente nos livros didáticos. Reconhecimento dos construtores das grandes metrópoles dando-lhes o devido mérito e reconhecendo a mea culpa por parte de uma sociedade injusta, que esmaga culturas e identidades na busca por sustentação do mercado. Mobilização política, cultural, econômica, a fim de alcançar uma reparação adequada das perdas desse grupo social. Essas perdas se manifestam nos grandes latifúndios rurais e urbanos, nas inúmeras famílias pobres das grandes metrópoles, que não possuem as condições necessárias de educação de sua família, e que devem ser atendidos pela reforma agrária e por outros benefícios que adentram no campo da inclusão social.

\section{REFERÊNCIAS}

ALBUQUERQUE JR, D. M. A Invenção do Nordeste e outras artes. São Paulo: Cortez Editora, 1999.

ASSARÉ, Patativa. A Triste Partida. Intérprete: Luiz Gonzaga. In: LUIZ GONZAGA. O Homem da Terra. São Paulo: RCA Victor, p1980. 1 LP. Faixa 3.

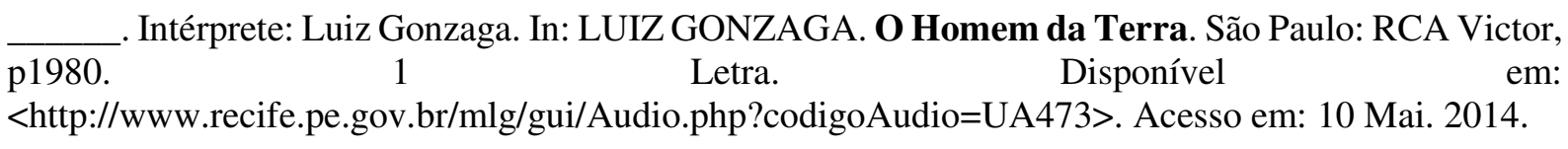

BULFINCH, T. Livro de Ouro da Mitologia - História de Deuses e Heróis. Rio de Janeiro: Editora Ediouro, 2006.

CALDAS, K. CAVALCANTI, A. Boiadeiro. Intérprete: Luiz Gonzaga. In: LUIZ GONZAGA. Olha Pro Céu. São Paulo: RCA Victor, p1951. 1 LP. Faixa 2.

Cigarro de Paia. Intérprete: Luiz Gonzaga. In: LUIZ GONZAGA. Luiz Gonzaga \& Fagner. São Paulo: RCA Victor, p1984. 1 LP. Faixa 8.

DANTAS, Z. GONZAGA, L. Vozes da Seca. Intérprete: Luiz Gonzaga, Fagner. In: LUIZ GONZAGA, FAGNER. Gonzagão \& Fagner 2 . São Paulo: RCA Victor, p1988. 1 LP. Faixa 10.

ABC do Sertão. Intérprete: Luiz Gonzaga, Fagner. In: LUIZ GONZAGA, FAGNER. Gonzagão \& Fagner 2 . São Paulo: RCA Victor, p1988. 1 LP. Faixa 1.

. A Volta da Asa Branca. Intérprete: Luiz Gonzaga. In: LUIZ GONZAGA. Eterno Cantador . São Paulo: RCA Victor, p1982. 1 LP. Faixa 5. 
DANTAS, Z. Acauã. Intérprete: Luiz Gonzaga, Fagner. In: LUIZ GONZAGA, FAGNER. Luiz Gonzaga \& Fagner. São Paulo: RCA Victor, p1984. 1 LP. Faixa 11.

DUSSEL, E.D. Etica da Libertação - Na Idade da Globalização e da Exclusão. São Paulo: Editora Vozes, 2005.

. La ética de la liberación - Ante el Desafio de Apel, Taylor y Vattimo, con respuesta critica inedita de K.-O. Apel. Cidade do México: Editora CICSyH, 1998.

. Filosofia da Libertação na América Latina. São Paulo: Edições Loyola, 1986.

FERNANDO, J. GONZAGA, L. Olha pro céu. Intérprete: Luiz Gonzaga. In: LUIZ GONZAGA. Quadrilhas e Marchinhas juninas. São Paulo: RCA Victor, p1965. 1 LP. Faixa 2.

FERREIRA, A.B.H. Novo Aurélio Dicionário da Língua Portuguesa Século XXI. Rio de Janeiro: Editora Nova Fronteira, 1999.

FREYRE, Gilberto. Casa-Grande e Senzala. São Paulo: Editora Global, 2004.

MARCOLINO, J. GONZAGA, L. Numa Sala de Reboco. Intérprete: Luiz Gonzaga. In: LUIZ GONZAGA. A Triste Partida. São Paulo: RCA Victor, p1964. 1 LP. Faixa 6.

MIRANDA, A.L. Hacia una ética de la Liberación: Las contribuiciones del pensamiento de Enrique Dussel. In: Simpósio: PENS/EDU - 3 - PENSAMIENTO LATINO AMERICANO Y DEL CARIBE: SIGLO XXI. Bruxelas, 2007.

RIBEIRO, D. O Povo Brasileiro. São Paulo: Editora Schwarcz, 2013.

ROXO, A. GONZAGA, L. O Cheiro Carolina. Intérprete: Luiz Gonzaga, Fagner. In: LUIZ GONZAGA, FAGNER. Gonzagão \& Fagner. São Paulo: RCA Victor, p1984. 1 LP. Faixa 8.

SAMPAIO, P.A. STEDILE, J.P Os Períodos da História do Brasil. História, Crise e dependência do Brasil. São Paulo: 5a Edição, Consulta Popular, 2003.

SILVA, J. MOCÓ, Z. São João Sem Futrica. Intérprete: Luiz Gonzaga. In: LUIZ GONZAGA. Danado de Bom. São Paulo: RCA Victor, p1984. 1 LP. Faixa 4.

VALENÇA, N. Coronel Pedro do Norte. Intérprete: Luiz Gonzaga. In: LUIZ GONZAGA. São João Quente. São Paulo: RCA Victor, p1971. 1 LP. Faixa 5. 